\section{Emergency management of major bleeding in a case of maxillofacial trauma and anticoagulation: utility of prothrombin complex concentrates in the shock room}

\author{
Alessandro Morotti, \\ Mauro Felice Frascisco \\ Department of Internal Medicine, San Luigi \\ Hospital, University of Turin, Italy
}

\begin{abstract}
Life-threatening bleeding in anticoagulation with Warfarin is an emergency challenging issue. Several approaches are available to treat bleeding in either over-anticoagulation or proper-anticoagulation, including vitamin $\mathrm{K}$, fresh frozen plasma and prothrombin complex concentrates (PCC) administration. In coexisting trauma-induced bleeding and anticoagulation, reversal of anticoagulation must be a rapid and highly effective procedure. Furthermore the appropriate treatment must be directly available in each shock rooms to guarantee the rapid management of the emergency. PCC require a simple storage, rapid accessibility, fast administration procedures and high effectiveness. Here we report the utility of PCC in management of a craniofacial trauma in proper-anticoagulation.
\end{abstract}

\section{Introduction}

Life-threatening bleeding in over-anticoagulation or proper-anticoagulation with Warfarin is an emergency challenging issue. Several patients require chronic administration of anticoagulant therapy rendering them more prone to spontaneous and trauma-induced bleeding. ${ }^{1,2}$ Strategies for treatment or prophylaxis of vitamin K over-anticoagulation include withholding the vitamin $K$ antagonist, administration of vitamin $\mathrm{K}$ itself, replacement the deficient factor with prothrombin complex concentrates (PCC) or fresh-frozen plasma (FFP) and, even if controversial, by using recombinant Factor VII. PCC contain vitamin-K dependent clotting factors (coagulation factor II, factor IX, factor X and factor VII). The choice of the appropriate treatment relies on the levels of over-anticoagulation and on the eventual bleeding, as reported in several guidelines. ${ }^{3-6}$ In the case of trauma and over-anticoagulation, treatment is generally an emergency procedure and therefore the choice should be focused on an easily accessible drug able to induce a rapid reversal of anti-coagulation. Although effective in re-coagulation, FFP requires compatibility testing and carries the risk of blood borne infection and transfusionrelated acute lung injury. FFP is frozen and requires at least $20 \mathrm{~min}$ to thaw. FFP administration is a long procedure therefore being unfit for the emergency setting. Moreover, faster accessibility to FFP is available only in those hospital with a Blood transfusion division. Finally, the risk associated with large volumes of FFP infusion cannot be ignored. On the contrary, PCC require a simple storage, rapid accessibility and fast administration procedures. Lastly the volume of solution is dramatically smaller than in the case of FFP. Currently, there is little published evidence to support the use of PCCs in the management of trauma-related massive bleeding. The results of one retrospective analysis demonstrated that in trauma patients receiving warfarin, the addition of PCC treatment to FFP and vitamin $\mathrm{K}$ treatment yielded a more rapid INR reversal; however, no clear improvement in clinical outcomes was noted. ${ }^{7}$

\section{Case Report}

Here we report a case of an emergency management of a craniofacial trauma in a anticoagulant treated patient. A 50 years old patient was admitted to our shock room after a high dynamic impact. Patient was suffering a severe maxillofacial trauma. The hemodynamic status was stable and an extendend-FAST-sonography was negative for pericardia effusion, hemoperitoneum and pneumothorax. Accordingly to trauma guidelines, a total body CT scan was therefore performed to evaluate internal lesions and to assess the extension of the craniofacial trauma. No intracranial hemorrhages were observed. A severe trauma of the zygoma and the frontal bone with the involvement of orbital floor was appreciated. Furthermore patient was suffering lung contusion. Meanwhile the CT was performed, blood examination showed a prolonged INR value (2.5) in a patient that we subsequently discovered to be in anticoagulation for a thrombophylic status. Accordingly to the high risk of bleeding extension inside the orbits, with a potential damage of the optical nerves and a consequent visual defect, PCC (Uman Complex, Kedrion, Lucca, Italy) were therefore rapidly administrated accordingly to standard dosage during the first hour of evaluation of the patient in the emergency department. At the end of the procedure, INR was set at a normal value. In the following hours patient was evaluated by a maxilla-facial surgeon for the specific treatment of the fracture. Non visual defect were ever occurred due to the trauma and hemorrhage.
Correspondence: Alessandro Morotti, Department of Internal Medicine, San Luigi Hospital, University of Turin, Regione Gonzole 10, 10043, Orbassano (T0), Italy.

Tel.: +39.011.902.6836.

E-mail alessandro.morotti@unito.it

Key words: life-threatening bleeding, anticoagulation, prothrombin complex concentrates.

Contributions: AM was involved in the management of the patient and wrote the case report; MFF reviewed the manuscript.

Conflict of interests: the authors declare no potential conflict of interests.

Received for publication: 4 October 2014. Accepted for publication: 18 February 2015.

This work is licensed under a Creative Commons Attribution NonCommercial 3.0 License (CC BYNC 3.0).

(C) Copyright A. Morotti and M.F. Frascisco, 2015 Licensee PAGEPress, Italy

Hematology Reports 2015; 7:5656

doi:10.4081/hr.2015.5656

\section{Discussion and Conclusions}

This case is an example of real-life emergency management of trauma induced bleeding in an anticoagulant treated patient. Patient needed to be rapidly re-coagulated in order to prevent visual defects before any potential surgical treatments. PCC represented the best treatment option because it could be administrated to the patients in an immediate timeframe. FFP administration would have required a much longer time due to the need to determinate blood group, thaw and administration of a large volume of plasma. FFP is also generally available in a rapid manner only in those hospital where a transfusion division is available. Our experience strongly suggests that PCC are the standard therapy for bleeding in anticoagulant patient and elevate PCC as common drug in each shock room.

\section{References}

1. Marzolini M, Wynne H. Should patients manage their own oral anticoagulation therapy? Rev Clin Gerontol 2002;12:275-81.

2. Warkentin AE, Donadini MP, Spencer FA, et al. Bleeding risk in randomized controlled trials comparing warfarin and aspirin: a systematic review and meta-analysis. J Thromb Haemost 2012;10:512-20.

3. Pernod G, Godiér A, Gozalo C, et al. for the 
working group members. French clinical practice guidelines on the management of patients on vitamin $\mathrm{K}$ antagonists in atrisk situations (overdose, risk of bleeding and active bleeding). Thromb Res 2010;126:e167-74.

4. Ansell J, Hirsh J, Hylek E, et al. Pharmacology and management of the vitamin $\mathrm{K}$ antagonists.. American College of Chest Physicians evidence-based clini- cal practice guidelines (8th edition). Chest 2008;133:160S-98S.

5. Baker RI, Coughlin PB, Gallus AS, et al. Warfarin Reversal Consensus Group. Warfarin reversal: consensus guidelines, on behalf of the Australasian Society of Thrombosis and Haemostasis. Med J Aust 2004;181:492-7.

6. Baglin TP, Keeling DM, Watson HG, British committee for standards in Haematology.
Guidelines on oral anticoagulation (warfarin): third edition - 2005 update. $\mathrm{Br} \mathrm{J}$ Haematol 2006;132:277-85.

7. Chapman SA, Irwin ED, Beal AL, et al. Prothrombin complex concentrate versus standard therapies for INR reversal in trauma patients receiving warfarin. Ann Pharmacother 2011;45:869-75. 